\title{
ACTIVE CONTROL TRANSPORT DESIGN CRITERIA
}

\author{
Bertrand M. Hall \\ McDonnell Douglas Astronautics Company \\ and \\ Robert B. Harris \\ Douglas Aircraft Company
}

INTRODUCTION

\begin{abstract}
The question of design criteria for active control transports is one of the key issues involved in the design. The reason for this is that if one is to realize benefits in the form of increased range, decreased weight, etc., he must be able to apply design criteria which take into consideration the design improvements afforded by active controls. The work presented in this paper draws heavily from the report of an industry panel sponsored by NASA in 1972-73 to study vehicle design considerations for active control applications to subsonic transports. This work is soon to be published in a NASA document, reference 1. Additional background material has been drawn from references 2 through 16, which are not cited individually. In this paper today we will define what is meant by active control and then define those functions winch were considered by this panel and should be considered in any detailed study of design criteria. We will also touch briefly on the FAA regulations governing transport aircraft design.
\end{abstract}

ACTIVE CONTROE TECHNOLOGY

The question of just what kind of an airplane configuration satisfies the definition of an active control aircraft is difficult. Several designations for this type of aircraft have been used (fly by wire, CCV, etc.) but an aircraft utilizing active controls can, in general, be identified as one in which significant inputs (over and above those of the pilot) are transmitted to the control surfaces for the purpose of augmenting vehicle performance. These inputs, derived from various sensors and properly processed, can be utilized to provide reduced trim drag and tail area through stability augmentation, reduce structural fatigue, alleviate maneuvering loads, suppress flutter, and improve ride comfort. If applied in a meaningful manner early in the vehicle design, ACT can have a significant impact on vehicle weight and geometry, thus leading to the designation of a "control configured vehicle" (CCV).

The term "fly by wire" describes a method of system implementation whereby electrical comnands are used. This approach is suited to the application of active controls in that it provides an ideal interface between the basic 
command system and the sensor and signal processing elements.

One frequently reads in the literature items which would lead one to believe that the active control transport will be a sudden and rather drastic innovation from the long line of transport development over the last 40 years. As a matter of fact, it is not a sudden transition, but a continuing growth in the technology of transport aircraft design. Every modern day aircraft, to some extent, incorporates some of those functions which we rather loosely tie together under the name of active control technology. It became apparent in the early twin engine transports that the pilot had difficulty exerting sufficient stick force to move the control surfaces of the aircraft. The designers rather ingeniously provided the pilot with aerodynamic tabs in order to reduce his workload and make the aircraft easier to control. As aircraft continued to grow, hydraulic-powered control systems were implemented. Although these early systems were designed in a manner which still provided the pilot with a mechanical linkage to the surface in the event of hydraulic failure, the modern day transports (the DC-10, L1011, the 747) now completely depend on the hydraulic system, and the designer (and the pilot) must rely on the reliability of the redundant systems which supply the power for the contro1 surfaces.

Along with this reliance on hydraulic systems, the pilot has also experienced an increase in cockpit workload from the many other systems which must function properly for the economical and safe operation of the large transport aircraft. In return, flying qualities and comfort have improved, reducing pilot effort and fatigue. The pilots are slowly learning to accept the fact that certain critical conditions must be automatically detected and appropriate remedial action taken without pilot activity. In this context then, the incorporation of further active controls on the transport aircraft is not a sudden transition but a steady progression toward a more modern and efficient transport design.

Design criteria and FAA safety regulations have generally responded to design innovations such as active control rather than leading these technical advances. It is important at this time, with active controls of various kinds becoming more and more common, that design criteria and Federal safety regulations lead the effort rather than follow these new designs. The panel concluded that most of the immediately available active control techniques have been well explored theoretically and, in fact, have been and are being demonstrated each day on a wide variety of experimental and military aircraft. This demonstration program is illustrated in Table 1.

The important conclusion to be drawn from this table is that when discussing active control technology, one is dealing with a technology which in some cases is well advanced, including operational experience on transport aircraft. Certainly if one compares this, say for instance, to the introduction of jet engines on aircraft, one would be forced to the conclusion that the relative state of readiness of active controls approaches that of jet engines at the time they were introduced into commercial aircraft. It is also important to note, however, the disparity between the status of various functions. For instance, the yaw damper is well received and in fact may be 
mandatory for safe handling qualities, and has many thousands of transport flight hours behind it. On the other hand, flutter control is by comparison only in its infancy. This leads to the conclusion that we must approach active control technology not as an all-inclusive blanket addition to an aircraft, but in a step by step procedure with each new subsystem being carefully verified on the basis of cost effectiveness, need, and reliability.

The above table does not consider the experience gained in the many missiles and spacecraft, both manned and unmanned, which have flown with complete automatic control and hands-off operation. Every Apollo mission from launch to splashdown is a demonstration of active control technology. The rapidly increasing technology of remotely piloted vehicles is also quickly adding to the storehouse of knowledge on how to take off, land, and navigate in a hands-off, completely automatic mode. Indeed, one must consider that more than 25 years ago the first hands-off flight of an aircraft was demonstrated from takeoff to landing.

ACTIVE CONTROL FUNCTIONS

Relaxed Inherent Stability

Relaxed inherent stability is conventionally defined as a reduction in the stability of the short-period attitude modes of rigid-body aircraft motion. That is, reductions in inherent stability result from the reduction of aerodynamic restoring moment with respect to angle of attack or angle of sideslip or a reduction of aerodynamic damping for the unaugmented (basic) aircraft. In principle, relaxed inherent stability can also refer to reduction in stability for other modes of aircraft motion.

This is a very important departure because the basic stability parameters in both the pitch and yaw axes have established the criteria for a considerable portion of the aircraft design. It is, however, one of the prime areas for the application of active control technology. Desirability of relaxed inherent stability arises from the possibility that with smaller tail volumes significant reductions in total aircraft drag and gross weight can be realized with invariant payload and mission. This is substantiated by the results of industry ATT and AST studies which show that relaxed inherent stability combined with center of gravity control offers the largest payoff for the aircraft in terms of gross weight reduction.

\section{Pitch Stability}

Relaxed longitudinal stability is one of the largest areas of potential benefit to be derived from the application of active control technology. We will not, in this paper, go into the details of how one implements active controls for the relaxed stability condition, but we will discuss some of the design criteria involved. First, the basic considerations influencing wing location and horizontal tail surface size and location are affected. The horizontal tail area, for instance, is normally set for a conventional design 
to meet stability and control requirements over the desired center of gravity range. Typically, the forward center of gravity limit tail area requirements have been set by trim capability or by control required to develop maximum lift in the landing configuration. The critical condition depends on the type of control system selected, i.e., separate trim and control surfaces or a single surface providing both control and trim. Aft C.G. limit requirements have generally been set by minimum levels of static longitudinal stability. For the active control relaxed stability design, the horizontal tail area may be set by either the landing case or by the pitching moment required for takeoff rotation at forward C.G. and by the reduced level of stability or by the pitching acceleration required for control in the presence of gusts and other external disturbances at aft C.G. These points are illustrated in Figure 1. The active controlled aircraft is rebalanced with a farther aft center of gravity range and a smaller horizontal tail.

The deficiencies in inherent stability might be compensated for by augmenting $C_{M_{\alpha}}$ and $C_{M_{g}}$ : The degree of instability allowable will be determined not only by increasing stabilization control power requirements but also by the variation of trim drag. As the balancing tail load changes from a down load to an up load, the longitudinal component of the tail lift vector changes from a thrust to a drag, significantly increasing tail drag. Minimum trim drag usually occurs near zero static margin, as illustrated in Figure 2. The exact center of gravity location for minimum trim drag is dependent on the particular configuration and even on the wing aerodynamic design.

As shown in table 1, some experience has been gained with relaxed inherent stability. Many jet transports have augmented static longitudinal stability where the augmentation is a function of airspeed. However, the magnitude of relaxation possible with active control will change the design criteria. Perhaps one of the most disturbing ideas that accompanies this changing criteria is that we have now replaced the easily calculated inherent stability requirement with a possible pitching acceleration requirement based upon the rather uncertain magnitude of airplane response required under varying conditions of flight and levels of atmospheric disturbance.

Flying qualities criteria may also be affected by dependence on augmentation, especially in the pitch axis. These will be discussed later.

\section{Directional Stability}

As shown in table 1 , this is the area where active control has seen the largest and most widespread application in transport aircraft. We have seen the yaw damper (an augmented directional stability and control system would more completely describe the systems currently flying on large transport aircraft) progress from a system which was a nice passenger comfort add-on feature to a system which must be operating in order for the aircraft to be cleared for flight. Despite this, there is probably much less to be gained by relaxed directional stability than by relaxed longitudinal stability. Currently, vertical tails are sized to provide static directional stability, dynamic lateral-directional stability, and asymmetric thrust control. Minimum control speed criteria are either critical or close to it in sizing the vertical tail 
on most transport designs with wing-mounted engines. Selection of the minimum control speed criteria may be somewhat arbitrary, but two things are generally considered:

1) The air minimum control speed must be less than the landing approach speed at all gross weights.

2) Ground and air minimum control speeds may dictate the minimum takeoff runway length and should be set to provide the desired capability.

With relaxed inherent stability and if asymmetric thrust control is not limiting, the tail size may be reduced to the level where stabilization control or airplane control response, as during a crosswind landing decrab maneuver, become limiting. In either case, new and unfamiliar design criteria are required.

\section{Control of Aircraft Center of Gravity and Inertia}

This area of active control has also been growing rather rapidly. At least one transport aircraft requires a sequence of wing fuel management in order to maintain the necessary margins against flutter. Maintenance of the C.G. within limits on current transports also dictates certain management sequences. It is therefore not a very great step to add to these procedures some requirements for maintaining an optimum C.G. location and/or inertia distribution for the actively controlled transport. It is this distribution of inertia for the entire aircraft as well as the equivalent C.G. location which acts with the control surface active control system to provide the optimum gains with relaxed inherent stability.

Automatic center-of-gravity control can offer significant design advantages in the following ways.

o Reduction of the design center-of-gravity range at given flight conditions may allow further reduction in the horizontal tail volume coefficient (refer to the indication of "CG range" on figure 1)

- Minimization of total drag with respect to center-of-gravity location during cruising flight, as illustrated in figure 2.

\section{Ride Quality}

Ride quality control refers to automatic control system functions which reduce to acceptable levels the accelerations to which passengers and crew are subjected. Factors such as low wing loading, poorly damped dynamic stability, structural flexibility, atmospheric turbulence, and high speed, low altitude flight all contribute to poor ride comfort.

Ride quality problems have tended to be secondary considerations with respect to resolution of structural load and flexibility problems. In fact, it was stated by two members of the panel that ride quality is not a major trade factor in design, because the criteria for ride quality in the commercial environment are:

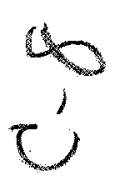


- Ride must be merely acceptable to passengers

- Ride must be competitive with contemporary commercial aircraft In addition, the aircraft must be readily controllable in turbulence.

The control techniques for improving ride quality are fairly well established both theoretically and operationally. Many commercial transports have some degree of ride quality control provided by means of conventional control surfaces. The yaw damper systems of modern jet transports improve ride quality even though their fundamental purpose is to improve handling qualities.

Active control for gust load alleviation has demonstrated greatly reduced response to turbulence, thus assuring a greater comfort for passengers. A typical reduction in aircraft response to turbulence obtained during the $\mathrm{B} 52$ LAMS and CCV programs is shown in Figure 3. It will be noted that the decrease in response to turbulence is sensitive to the aircraft structural modes and that a uniform reduction at all frequencies is impossible. This led to a good deal of discussion among the panel members as to the criteria for ride quality. While certain maximum limits for ride comfort are relatively easy to establish, the panel decided that detail criteria for ride comfort still need a considerable amount of research in order to establish workable design criteria. In either case it is doubtful that ride quality design criteria will result in weight savings, so the competitive pressure to supply a smoother ride will probably dictate the control system design criteria.

Load Control

Load control refers to the use of passive or automatic control functions for the purpose of regulating the net load and distribution of load applied to the aircraft structure.

There are four main facets of load control. To some extent, all must be considered simultaneously to achieve a well-balanced design although some may receive considerably more emphasis than others. Three facets of load control which are specifically discussed in this subsection are maneuver load control, gust load control, and fatigue damage control. Flutter control might also be included as a fourth facet of load control because flutter is the result of a particular kind of loading. Flutter, however, tends to be disassociated from other types of loading for reasons which will be explained in the flutter con- trol subsection which follows.

The question of load control was perhaps as controversial as the question of relaxed inherent stability, and several important points were raised regarding each type of load control.

Maneuver Loading

Maneuver loading is that portion of forces acting on the airframe which result from maneuvers required to maintain the aircraft on the intended flight path. The distribution of this loading over the airframe can have a powerful effect upon the shear forces and bending moments which must be transmitted at 
given points in the structure. The ability to tailor the distribution of maneuver loading over the airframe is maneuver load control. Maneuver load control can have a significant impact upon structural implementation and even upon configuration.

The impact of tailoring maneuver load distribution may be far-reaching. If the maximum reduction in fatigue loading is to be achieved, maneuver load control would be desirable during all maneuvering. When applied to the wing, this usually implies an "unloading" of the outer wing, thus reducing the root bending moment, as illustrated in Figure 4a. A high wing loading transport may possibly be limited in cruise altitude by maneuver requirements such as those specified in the British Civil Airworthiness Requirements. Unloading a portion of the wing would tend to reduce maneuver capability, particularly if wing stalling occurs inboard. Thus, maneuver load control might tend to limit wing loading or dictate a new approach to wing aerodynamic design. This situation may be avoided by utilizing maneuvering flaps to increase lift on the inboard portion of the wing, Figure 4b. Additional aerodynamic and structural design considerations would still be required, along with new modes of control akin to direct lift control.

Gust Loading

Gust loading is that portion of forces acting on the airframe which result from atmospheric disturbances.

Gust-load control is accomplished by the following means:

- Controlling the aircraft in such a way as to produce a net incremental load factor which tends to cancel the net gust-induced load factor. Because of aircraft inertia, this is best accomplished with direct lift control devices.

- Controlling the distribution of the incremental load which tends to cancel the gust-induced load in such a way that their distributions are similar.

o Augmenting damping for modes excited by gusts.

The extent to which gust-1oad control is effective in performing all three listed functions can have a significant impact upon the structural strength and fatigue requirements.

Experience cited for the panel indicated that the impact of maneuver and gust-load control on reduction of structural requirements tends to be significant only when both maneuver and gust-load control are practiced simultaneously. If only one of these load-control objectives is addressed, then the other source of loading becomes critical before any significant reduction in structural requirements is realized.

\section{Fatigue}

Cyclical loading is produced by forces applied to the airframe which result in stress-level oscillations in the structure. Fatigue damage results 
from accumulated stress cycles at given stress levels and at critical points in the airframe. Fatigue damage control is a technique for reducing the fatigue damage rate by using active controls to reduce the number of transient cycles at the higher stress levels to which the structure is subjected during operation.

The frequency range of damaging loads extends from once per 100 flights (e.g., from very "firm" landings) to the once per flight of the so-called ground-air-ground (GAG) cycle and to the characteristic frequency of the response to turbulence. The transition between the ground mean loading and the airborne mean loading of the GAG cycle accounts for as much as $80 \%$ of fatigue damage on the lower wing skin on some contemporary transport aircraft. Most of the remaining damage accrues from incremental loads in the $1 / 4-$ to $1 / 2-\mathrm{g}$ range.

Since the mean-to-mean fluctuation of the GAG cycle is not amenable to control, active control offers potential reduction of longitudinal loads only for the incremental load fluctuation about the mean level of the GAG cycle. Large potential for load reduction exists for lateral loads because there is no GAG cycle effect.

Much of the panel discussion centered around the application of the classical, rather arbitrary approach of a discrete gust versus the more modern approach of "rational probability analysis" coupled with careful mission analysis. The majority of the panel agreed that we must go even further in developing statistical methods and performing mission analyses in order to realize the benefits to be gained from the application of active controls to load alleviation. The obvious point here is that if careful mission analysis is applied to the calculation of the fatigue life of the aircraft and if the load alleviation control systems are assumed active during the entire life of the aircraft, the weight of the aircraft structure could be reduced for the same fatigue 1ife. Studies confirming this are still in progress and it is difficult at this time to come up with definite criteria. However, the panel agreed that the combination of maneuver load control plus gust load alleviation can result in reductions of load fluctuation.

\section{Other Load Limiting}

Other forms of load limiting are also useful. Surface actuator capability not only limits the airplane maneuver envelope but tends to limit the maximum load on the surface itself. Many examples of load limiting are in use today on jet transports. Flap blowback or deflection limiting is in use on several aircraft to limit structural loads. Rudder deflection limiting as a function of flap angle and airspeed is also commonly employed. As other active control modes are used to reduce structural weight and margins, the use of these approaches will have to be considered in concert with the other control modes in a synergistic design procedure. 
Envelope limiting refers to those functions in an active control system that prevent or discourage operation of the aircraft outside its design or operating envelope.

Every transport aircraft currently has some form of envelope limit warning and envelope limiting, although not usually in the ACT sense. Envelope limit warning takes the form of stick shaker systems which warn of an approach to the stall and overspeed warning systems which warn that maximum operating speeds have been exceeded. Envelope limiting is provided by pilot strength limitations, control surface actuator capability, stick pushers, autopilot authority, and autopilot automatic cutoffs (ACO), for example. The limits provided by pilot or actuator strength may or may not be within the structural design envelope of the aircraft. For instance, the pilot does, in some flight regimes, have the capability of exceeding the design limit loads about all axes.

The concept of envelope limiting is now being applied to fighter aircraft to allow use of the full maneuver envelope without danger of a stall-spin departure. For transport aircraft, the incorporation of active control could supplement the present warning and limiting features with an automatic function which prevents the aircraft from entering into a forbidden flight regime. Angle of attack and sideslip limiting could avoid post-stall loads and flight characteristics problems, and reduce vertical tail loads. Overspeed Iimiting could reduce the required margin between maximum operating and design dive speeds, as shown in Figure 5, reducing design loads and allowing a lighter structure. The possibility of atmospheric-caused upset must be considered in establishment of minimum margins. It would then be necessary to assure that the flight control system will satisfactorily handle this job even in the backup or degraded operational modes to assure that the aircraft is operated within the criteria established for strength of the structure. The panel-felt, however, that G-limiting might not be desirable, as there have been several cases where the ability of an aircraft to exceed the design limit load factor may have avoided a catastrophic accident following upsets at low altitudes.

\section{Flutter Control}

Flutter control refers to the use of automatic control functions which alter the apparent structural mass or stiffness, or aerodynamic damping. It was the unanimous opinion of the panel that active flutter control must be considered as part of ACT even if it may not find commercial application in the near future. At present, the nature of the control law for achieving the required augmentation seems extremely sensitive to the unsteady aerodynamic forces and is also sensitive to the mass and stiffness distributions of the airframe. It should also be stressed that the flutter certification of the aircraft and the flutter safety margins will be influenced by the presence of other active control functions. For instance, in the case of relaxed inherent stability, it is necessary to have a relatively wide bandwidth control system to cope with the unstable short period mode roots. This control system will tightly couple with the basic flutter modes of the wing-nacelle-fuselage combinations on a large transport aircraft. This will mean that the safety 
margin criteria for flutter will be a function of the control system loop gains and general design. Criteria will also have to be carefully developed to account for backup modes of operation of the flight control system.

\section{DESIGN CONSIDERATIONS AND REGULATIONS}

Key elements in bringing ACT to the point of commercial application are:

- Availability of proven design criteria

- Limitations on ACT applications that may be imposed by regulations

- Availability of proven design practices to guide the combined application of ACT functions.

We are concerned mainly with the first two items in this paper.

Design criteria are derived from many sources. Perhaps the most important are the manufacturer's experience and design philosophy. Studies performed or financed by NASA and DOD provide a large fund of suggested criteria and data which the designer uses in selecting his criteria for application.

For military aircraft, mandatory military specifications are usually applied to obtain what are considered to be good characteristics. In the civil or commercial world competition usually ensures that the aircraft have the best characteristics obtainable, within reason. Safety is therefore the primary purpose of the airworthiness requirements contained in Part 25 of the Federal Aviation Regulations. These requirements must always be kept in mind, as they are the standard by which airworthiness of the aircraft will be judged, Besides the U.S. FAA regulations, the designer must also consider the requirements that may be imposed by other nations on aircraft offered for sale within their territory. Among nations having specific airworthiness requirements are the United Kingdom, France, the Netherlands, Germany, Italy, and Australia.

Existing Federal Airworthiness Regulations (FARs) in Part 25 do not place many significant constraints on the application of ACT. Those constraints which are imposed tend to be of the following kinds:

- Interpretations of the fundamental regulation intent were not made in a context which included ACT.

- Practical considerations for demonstrating compliance sometimes require arbitrary maneuvers, tests, or environments which have no counterparts in normal or degraded modes of operation.

o The view of acceptable safe practice tends to be consistent with the current or recent past state of the art but not to the projected state of the art.

Existing regulations [FAR $25.21(e)]$ already recognize that acceptable flight characteristics may depend upon a stability augmentation system or upon other automatic or power-operated systems. This clearly admits ACT systems as we11. Revisions to the regulations found necessary for ACT will probably initially take the form of special conditions for certification. 
In the following paragraphs we will discuss some of the important design criteria and regulatory problems affecting the implementation of ACT.

$$
\text { Reliability - Safety }
$$

The immediate reaction of most designers when faced with consideration of ACT is to raise the question of reliability and safety--"that thing isn't replacing structure in my airplane until it has demonstrated the same reliability as primary structure".

It is apparent that safety must not be compromised, and that the criteria for catastrophic failure will be basically unchanged. The required level of overall function reliability is achieved in control and vital power systems by increasing redundancy for those functions that do not have the desired reliability. For example, controllability of the wide-body jet transports is dependent on integrity of the hydraulically powered controls. Reliability for safety of flight is provided by multiple hydraulic systems. After some number of failures, it is, of course, advisable to terminate the flight at the nearest suitable airport in order to minimize exposure time in a non-redundant configuration.

One difference, however, is that failures of presently utilized active control functions do not usually result in reductions in structural capability under normal flight conditions, whereas proposed ACT functions will, in effect, replace primary structure. This does not necessarily mean that these functions must be as reliable as the basic structure, however. The strength requirements will be met already considering at least one failure, so that no reduction in necessary capability should occur for the first failure. An assessment of situation severity and a list of means available for reducing risks presented by failures in ACT functions is given in Table 2. There are three principal means of controlling the risk:

- Control system redundancy

- Actuation and/or surface authority distribution

- Reduced operating envelope

The u1timate levels of reliability will be required only for those functions upon which safe termination of the flight depends.

Autoland systems are presently achieving the required reliability, but for only a short exposure period during each flight. Figure 6 shows the required MTBF as a function of the number of systems required to achieve a probability of complete failure of not more than 1 × $10^{-9}$ during a three hour flight.

The problems with reliability are likely to occur within the sensing, computing, and display functions which are today largely restricted to flight guidance and control systems (FGCS). Typical MTBF values for these systems are in the order of 300 to 800 hours. Although individual system reliability improvement is still required, Figure 6 shows that the overall reliability goal may be satisfied with a reasonable number of redundant systems. Characteristic systems for this application will include multiple channel command paths in which failures will be annunciated, thus providing the pilot with system 
degradation information enabling him to take corrective action prior to total system failure. Ultimately however, improved reliability goals and techniques must be derived and imposed, but must always include a sensible system failure mode and annunciation capability.

An associated problem is the FAA requirement for determining that safetyrelated systems are functioning prior to dispatch. Difficulties in determining sensor status have prevented taking credit for automatic cut-offs (ACO) in limiting the consequences of autopilot hardover failures, in some cases. This will require design of systems which can be satisfactorily checked on the ground.

Reliability is presently established in a manner whereby elements of the system can be specifically identified in a reliability block diagram and the reliability of each element is available. The reliability of the avionics elements contributing to the flight safety of a control configured vehicle will be significantly more complex. Not only are there many more elements, but the software is an additional facet which must be evaluated. Accomplishing the failure and probability analyses of these complex systems is a major task in itself, and is not within the present state of the art for those ACT functions not yet fully developed. In some cases, failure analyses have been required to prove that certain types of failures were impossible, which in itself may be a nearly impossible task.

$$
\text { Reliability - Economics }
$$

The economics we refer to here is that of dispatch reliability, not maintenance costs, although the latter are certainly important.

A typical design goal for dispatch reliability is that, mechanically, the aircraft shall be capable of departure within 15 minutes of the scheduled time 99 percent of the time. This goal is very stringent and is currently being achieved consistently by only one transport aircraft, the DC- 9 . The design of this aircraft emphasized simplicity and reliability, whereas the design of later aircraft has emphasized performance, with a resulting increased complexity.

This dispatch goal produces a desire to have your cake and eat it, too. The benefits of more complex systems are desired but it is also desirable to allow dispatch with as many things as possible inoperative or missing. It is common to find flight manuals and minimum equipment lists filled with information for covers, doors, and fairings missing or for hydraulic pumps, yaw dampers, Mach trim systems, autopilots, antiskid, and thrust reversers inoperative. In many cases, the benefits to be obtained from, and therefore dependency on, some systems are limited by the criteria for inoperative dispatch.

The goal of $1 \%$ delay rate is typically allocated among the various aircraft systems as shown in Figure 7. The pilot controls and FGCS are allotted $0.005 \%$ and $0.10 \%$, respectively. The small size of these percentages does allow some increase without having a major impact on delay rate, but the accompanying impact on maintenance and spares availability may be significant. 
Design criteria for flight characteristics, or flying qualities of transport aircraft seem to be in good shape, judging by pilot acceptance of the wide-body jet transports. There has been a steady improvement in flying qualities but, at the same time, some increase in the possible number of degraded situations due to increased system complexity and failure modes.

Transport aircraft flying qualities research in the U.S. has received more of the attention it deserves in recent years after previously having to try to adapt fighter-derived criteria.

Since transport aircraft tend to be developed by evolution rather than revolution, their flying qualities and criteria tend to evolve similarly. The FAA regulations concentrate on classical stability characteristics, primarily static, and on steady state control requirements. Control response and aircraft dynamics receive scant mention, although awareness is much higher during actual aircraft evaluation. The need for positive static stability is still debated, but is defended on the grounds of safety, i.e., reduced pilot workload and fatigue plus a tendency to stay put or even recover from a disturbance during periods of inattention.

Automatic and augmented flight control systems have tended to evolve along a line different from that of basic or inherent flight characteristics and control modes. With the advent of fully-augmented active control systems, it is time that the proper modes and parameters be determined.

The primary axis of concern is the pitch axis. In the past, the provision of adequate inherent pitch stability has tended to emphasize long period characteristics: static longitudinal stability, longitudinal maneuvering stability, and speed or flight path stability. When these characteristics are satisfactory, and the configuration is a relatively conventional one, dynamic stability (short period mode) is generally completely satisfactory. The elevator or longitudinal control is, over the long term, an airspeed control and the throttles are primarily a flight path control in straight flight; in a somewhat simplified sense. In actual practice, thrust changes usually produce some trim change also, thus affecting the trimmed airspeed. With the usual nose-up trim change with increased thrust, applying forward throttle will actually result in a slower airspeed but an increased climb angle.

The initial response of the aircraft to rapid control usage is not the same as the final effects on trimmed flight, however. Elevator inputs produce a change in angle of attack, seen by the pilot as an attitude change, which only gradually manifests itself as a change of airspeed. The inmediate normal acceleration and the ultimate change in airspeed will cause a change in flight path and, as a result, in altitude unless the throttles are adjusted to maintain the long term path.

Advancing the throttle produces an initial acceleration which is gradually transformed into a change in flight path angle unless restrained by the elevator control. If there is a large effect of thrust on pitching moment, attitude changes will also occur. 
Because of these immediate responses, the controls are used in this manner when accurate flight path tracking is required over the short term. In fact, many pilots believe this is the only correct definition of the control modes.

The usual implementation of automatic flight control systems has been based on this short-term control response. Autopilots on propeller-driven and early jet transports typically incorporated attitude and altitude hold modes. Later autopilot designs incorporate vertical speed, airspeed, and Mach hold modes, the latter two more in the line with the long term elevator-as-airspeedcontrol principle. Later autopilots also include turbulence modes, usually a loose attitude hold with pitch rate damping. This mode evolved from experience when it was determined that attitude control offered the best chance of avoiding upsets when flying in turbulent or stormy weather.

The advent of the autothrottle system, which tries to maintain airspeed with the throttles, dealt a body blow to the elevator-airspeed control proponents. The final blow was administered by the introduction of control wheel steering (CWS), in which the pilot flies the airplane through a rate command, attitude hold mode of control. This system can reduce the pilot's workload because the airplane is essentially always in trim when the controls are released.

What is the effect of these control modes? Since the elevator is inherently a displacement control, mechanizing it as a rate control significantly changes the airplane's characteristics. Conventional maneuvering stability and static stability become meaningless, as the airplane has neutral or no stability in terms of these flight parameters. Singly or in combination, autothrottles and CWS can produce neutral or divergent flight path stability on what would otherwise be a stable aircraft. This is graphically illustrated in Figure 8, which shows airplane response following a pilot-induced upset during landing approach. The basic airplane, Figure $8 \mathrm{a}$, is inherently stable and recovers to the trim attitude and airspeed. With autothrottles engaged, $8 \mathrm{~b}$, the attitude and flight path diverge following the upset. Control-whee1steering, 8c, prevents attitude divergence but also maintains the airplane at the commanded upset attitude as the flight path diverges. To the credit of CWS, it must be said that it is much less susceptible to external disturbances than to pilot-induced upsets.

These CWS systems do not allow compliance with the stability requirements of FAR 25.173 and .175. They have been certificated basically as autopilot control modes under the requirements of FAR 25.1329 and Advisory Circular 25.1329-1A. They are not considered as primary control modes and have therefore not been evaluated against the basic stability requirements. These requirements therefore present a possible problem area in the implementation of active controls, depending on the control modes selected.

Two types of augmentation would be required to match inherent stability characteristics: angle of attack stability and pitch damping. The latter is fairly easily accomplished but the former requires direct measurement or a combination of measurement and computation. Computed angle of attack is within the current state of the art, although accuracy of either computed or measured 
a may be marginal for use at high airspeeds. In any case, considerable work needs to be done to specify the proper flying quality parameters for airworthiness evaluation. Both the industry and the FAA are active in this area and some changes may result from the formal review of the regulations to be held later this year.

The envelope limiting function of ACT may also negate the regulation stalling speed and characteristics requirements. It would seem appropriate in this event to substitute the control limited minimum speed concept.

\section{Structures}

The basic impact upon structural design criteria due to the application of active control is in the area of structural loads. In this area it is not only desirable but also feasible to retain a considerable portion of the structural design criteria which have led to the current generation of transport aircraft. For instance the 1-cos gust, as currently applied to aircraft load calculations, is perhaps not conceived on the most rational basis, but it nevertheless serves as a standard, and it is not necessary to modify it just to permit active controls in the design.

Maneuver design criteria, on the other hand, should be reviewed for active controls application. For instance, the basic $-1,+2.5 \mathrm{~g}$ load factor criterion is deeply entrenched in our current transport design philosophy and designs major portions of the structure. Instances are cited where transport aircraft have had to develop this maximum load factor in order to survive an upset. These instances caused the panel to adopt a negative position on $\mathrm{g}$ limiting, as mentioned previously. From a design criteria standpoint we need to re-examine the conditions leading to these maximum load factor maneuver requirements and determine whether active controls prevent one from ever getting into this region or perhaps whether active controls can cause even more exaggerated maneuvers. In either case the change in structural weight of the aircraft as a function of this maneuver requirement is considerable.

Another instance where criteria changes are necessary is in the computation of aircraft fatigue life. Here again a considerable portion of structure is designed for fatigue, and as in the maneuver load factor case, the active control system has a considerable influence over aircraft structural response and hence fatigue life. It is not clear that the practical active control system will necessarily reduce the response (and hence the structural weight) of all portions of the aircraft, but it is clear that future criteria must deal directly with the input data required to perform rational probability and mission analysis studies. This conclusion was strongly supported by the pane1.

Another instance where new structural design criteria must be developed for the active controlled aircraft is in the area of abrupt maneuver requirements. The loads developed on the structure during the abrupt maneuver will be very dependent on how one chooses to mechanize the control system. For instance the transient loads developed during an abrupt time sequence of elevator deflections may be considerably different from the transient loads 
developed during a similar deflection history of a flying tail, although each may produce roughly the same aircraft C.G. acceleration. For the aircraft which depends on a functioning active control system at all times the abrupt maneuver criteria must deal with defining the conditions which cause the abrupt maneuver, rather than defining the control surface time history. The following are examples of these modes

a) Transient caused by switching from primary to backup systems

b) Transients caused by control system failure modes such as, "hardover command".

c) Evasive action for collision avoidance.

\section{Control Systems}

The criteria for detail design of conventional control systems are predominantly developed by the manufacturers. These include instructions regarding design to provide safety, ease of maintenance, and to prevent incorrect assembly, for example. The implementation of active controls will necessitate the expansion of these rules to include much more sophisticated applications. In the past (with the possible exception of the yaw damper) transport aircraft have been designed and certified to operate without an operational autopilot. For the actively controlled transport the flight controller becomes a primary design consideration along with structures, aerodynamics, and propulsion systems. It should be noted, however, that a start in this direction is being made with the design of the YC-14 and YC-15 advanced medium STOL transport prototypes.

One area which received considerable attention from the panel is that of establishing a math model of the airframe and deriving design criteria for establishing parameter perturbation analyses on the model. This is an area that has received considerable attention in missile and launch vehicle control system design. Unsteady aerodynamics and structural dynamic parameters were singled out by the panel as being the principal problem areas. It was felt that the accuracy of existing prediction methods was inadequate for optimum ACT system design. This problem is being approached by improving the methods and by exploration of insensitive flight control systems. A related problem is the variation in structural dynamic and aerodynamic parameters due to changes or differences in fuel and payload distribution that may occur during one flight as well as between flights, along with the variation of airspeed, altitude, and Mach number encountered. Again, the insensitive approach may prove to be the best way to handle this variation in parameters.

The active control system will also be much more demanding on control system components which are subject to wear. Because of the higher gains required by the active control system, control system components will have to meet tighter specifications, and remain within these specifications throughout the useful life of the control system. This requires new design criteria for components such as hydraulic valves and actuators whose phase and gain characteristics are affected by wear. It will also require tighter tolerances on control surface hinges in order to prevent low amplitude, fatigue causing, limit cycle oscillations. At the same time, the automatic controllers must handle out-of-tolerance conditions. These conditions can occur due to 
manufacturing tolerances, aging, wear, material failures, off-nomina1 power supplies, and dynamic characteristics caused by changes in environmental conditions.

As flight control systems become more complex, built-in test equipment (BITE) takes on greater importance as a means for improving safety, operational reliability, and maintenance costs. The design requirements for built-in test equipment must include not only static end to end checks of the control system but dynamic checks as well. The BITE requirements should include the capability for these status and performance checks by continuous on-1ine tests, inflight pre-engage operational status tests, channel comparison monitoring, and ground maintenance tests. The inflight tests must be capable of detecting failures to the functional system level. The ground checks must isolate failures to the line replaceable unit (LRU) level. The complexity of the systems as compared with the level of capability of average maintenance personnel will require very stringent design requirements to preclude faulty maintenance and provide ease of fault isolation and correction. It is important to note that the background of missile control system experience will do little to help us formulate design criteria associated with many hours of continuous operation.

As one of the special conditions in the transport certification procedure, it is specified that the airplane will operate safely for at least 5 minutes with the primary electrical system inoperative. The current means of complying with this requirement should not be seriously impacted by the incorporation of additional ACT functions. For instance, several aircraft have air-driven electrical generators for emergency use, and the addition of more ACT functions will only add to the electrical load.

FAR 25.671 requires that the aircraft be controllable if all engines fail. Here again the current means for supplying electrical and hydraulic power, in the event of all engines having failed, should be sufficient to satisfy the needs of additional ACT functions.

\section{CONCLUSIONS}

It is clear from the information outlined in this paper and from the work of the NASA Pane1, that a great deal of work remains to be done in the area of detail design criteria and design practice. It is also apparent that the overall improvement that one can achieve by going to active controls is, with but a few exceptions, not being held back by current regulations and basic design criteria.

The area where the most work needs to be done is in the detail design criteria of the control system itself. The problems center around the derivation of reasonable design criteria for the design of advanced flight controllers. Other problems are the achievement of the reliability goals and production of hardware which can be maintained and manufactured at costs comparable to the rest of the aircraft critical components. 
As this work progresses, more ACT functions will be proven to be both reliable and practical, and will be incorporated into the advanced transport designs.

\section{REFERENCES}

1. Hoffmann, L.G., and Clement, W.F.: Vehicle Design Considerations for Active Control Application to Subsonic Transport Aircraft. NASA CR 2408 , Dec. 1973.

2. Anon: Airworthiness Standards: Transport Category Airplanes. FAR, Vo1. III, Part 25, Dec. 1969.

3. NASA ATT Executive Summary: Study of the Application of Advanced Technologies to Subsonic Long-Range CTOL Transport Aircraft. June 1972 .

4. Anon: Study of the Application of Advanced Technologies to Long-Range Transport Aircraft. Final Oral Reports. April 1972.

1. NAS1-10701 - Lockheed-Georgia Company

2. NAS1-10702 - General Dynamics-Convair Aerospace Division

3. NAS1-10703 - The Boeing Company - Commercial Airplane Group

5. Holloway, R.B.: Introduction of CCV Technology into Airplane Design. D3-9210, The Boeing Company, Wichita, Kansas. Oct. 1973.

6. Roberts, L.D., and Johns, R.E.: Military Transport Fly-By-Wire. AFLCWPAFB-APR 74100 .

7. Pasley, L.H., and Rohling, W.J.: Compatibility of Maneuver Load Control and Relaxed Static Stability. AIAA Paper No. 73-791, Aug. 1973.

8. McKenzie, J.R.: B-52 Contro1 Configured Vehicles Ride Control Analysis and Flight Test. AIAA Paper No. 73-782, Aug. 1973.

9. Gilyard, G.B., and Holleman, E.C.: In-F1ight Pilot Evaluations of the Flying Qualities of a Four-Engine Jet Transport. NASA TN D-6811, May 1973.

10. Wasserman, R., and Mitchell, J.F.: In-Flight Simulation of Minimum Longitudinal Stability for Large Delta-Wing Transports in Landing Approach and Touchdown. AFFDL-TR-72-143, Cornell Aeronautical Laboratory, Feb. 1973.

11. Goodmanson, L.T., and Gratzer, L.B.: Compatibility of Maneuver Load Control and Relaxed Static Stability. AIAA Paper No. 73-791, Aug. 1973. 
12. Holleman, E.C., and Powers, B.G.: Flight Investigation of the Ro11 Requirements for Transport Airplanes in the Landing Approach. NASA-TND-7062, Oct. 1972 .

13. Mooij, H.A., and DeBoer, W.P.: An Exploratory Study of Flying Qualities of Very Large Subsonic Transport Aircraft in Landing Approach. ICAS Paper 72-07, Aug. 1972.

14. Newberry, C.F.: Interaction of Handling Qualities, Stability, Control, and Load Alleviation Devices on Structural Loads Summary Report. AGARD-R-593, July 1972 .

15. Gabel, R., et al: Pilot and Passenger Vibration Environment Sensitivity. AIAA TIS $3 / 02,1971$.

16. Stein, G., and Henke, A.H.: A Design Procedure and Handling-Quality Criteria for Lateral-Directional Flight Control Systems. AFFDL-TR-70152, May 1971.

17. Holleman, E.C.: Flight Investigation of the Roll Requirements for Transport Airplanes in Cruising Flight. NASA TN D-5957, Sept. 1970. 


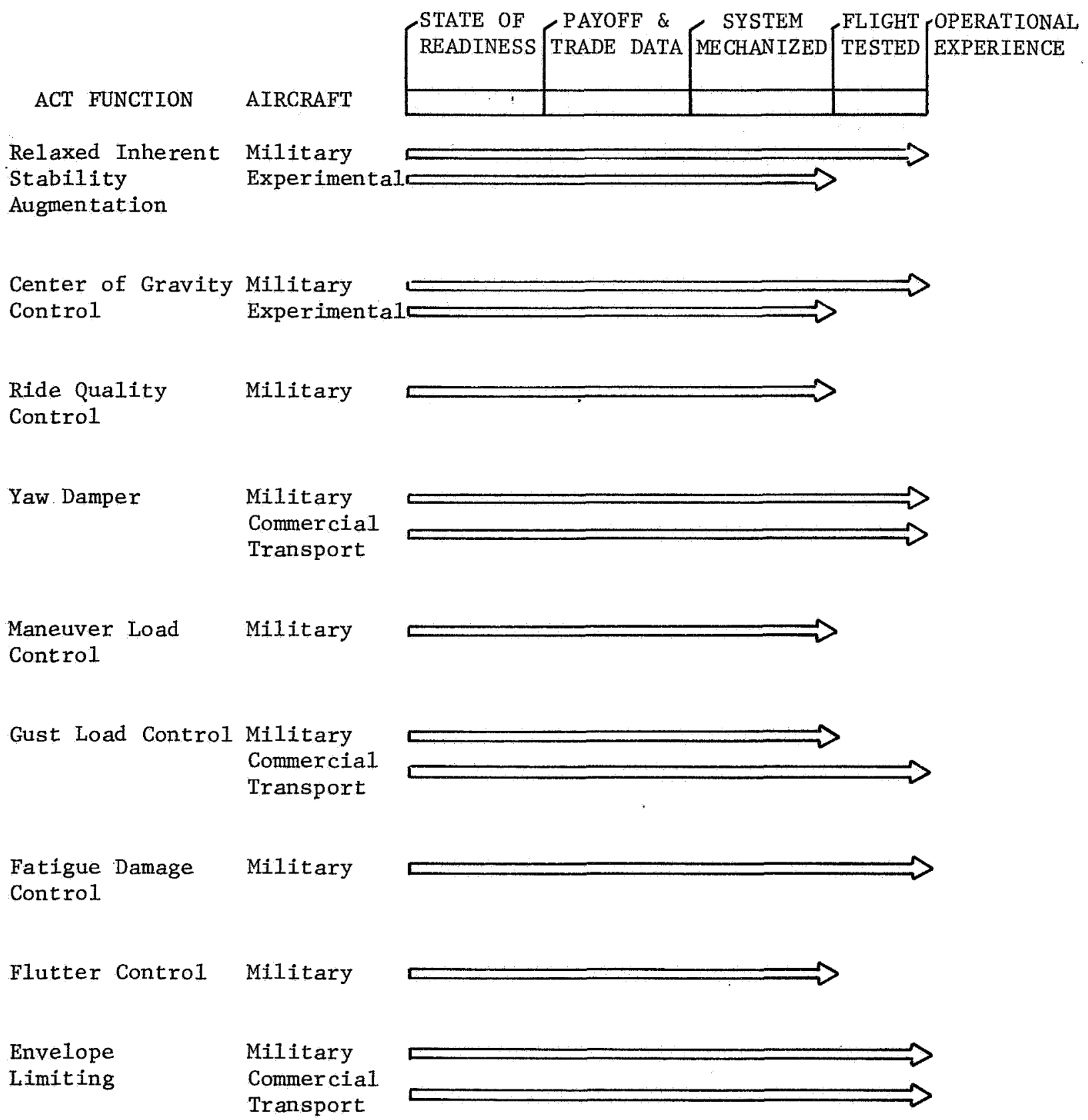


TABLE 2: DEGRADED SITUATION SEVERITY AND MEANS AVAILABLE

FOR MODIFYING RISKS PRESENTED BY FAILURES

\begin{tabular}{|c|c|c|}
\hline FUNCTION & $\begin{array}{c}\text { SEVERITY OF SITUATION } \\
\text { WITH FUNCTION } \\
\text { DEGRADATION }\end{array}$ & $\begin{array}{l}\text { MEANS AVAILABLE FOR MODIFYING } \\
\text { RISKS PRESENTED BY FAILURES }\end{array}$ \\
\hline $\begin{array}{l}\text { Relaxed Inherent } \\
\text { Stability Augmentation }\end{array}$ & Moderate-Very & $\begin{array}{l}\text { Redundancy + Authority distribu- } \\
\text { tion } \\
\text { Reduced operating envelope } \\
\text { CG management }\end{array}$ \\
\hline $\begin{array}{ll} & \text { Maneuver } \\
& \\
\text { Load } & \\
\text { Contro1 } & \text { Gust } \\
& \\
& \text { Fatigue } \\
& \text { Damage }\end{array}$ & $\begin{array}{l}\text { Negligible-Moderate } \\
\text { Negligible-Moderate } \\
\text { Negligible }\end{array}$ & $\begin{array}{l}\text { Redundancy + Authority distribu- } \\
\text { tion } \\
\text { Reduced operating envelope } \\
\text { Redundancy + Authority distribu- } \\
\text { tion } \\
\text { Reduced operating envelope } \\
\text { Reduced operating envelope }\end{array}$ \\
\hline Flutter Contro1 & Very-Extreme & $\begin{array}{l}\text { Redundancy + Authority distribu- } \\
\text { tion } \\
\text { Reduced operating envelope }\end{array}$ \\
\hline Ride Quality Control & Negligible-Moderate & $\begin{array}{l}\text { Redundancy + Authority distribu- } \\
\text { tion } \\
\text { Reduced operating envelope }\end{array}$ \\
\hline Envelope Limiting & Negligible-Moderate & $\begin{array}{l}\text { Redundancy } \\
\text { Reduced operating envelope }\end{array}$ \\
\hline CG Control & Negligible & Reducêd operating envelope \\
\hline
\end{tabular}




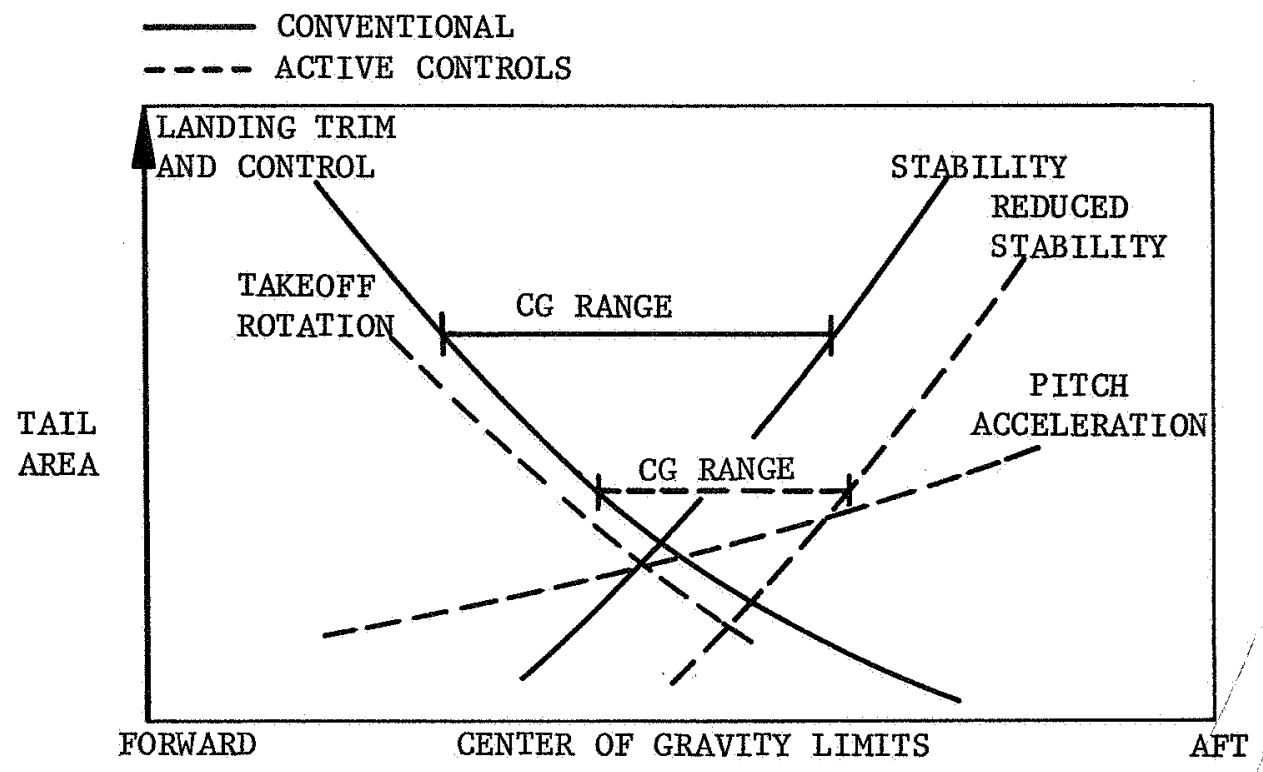

FIGURE 1. HORIZONTAL TAIL AREA REQUIREMENTS

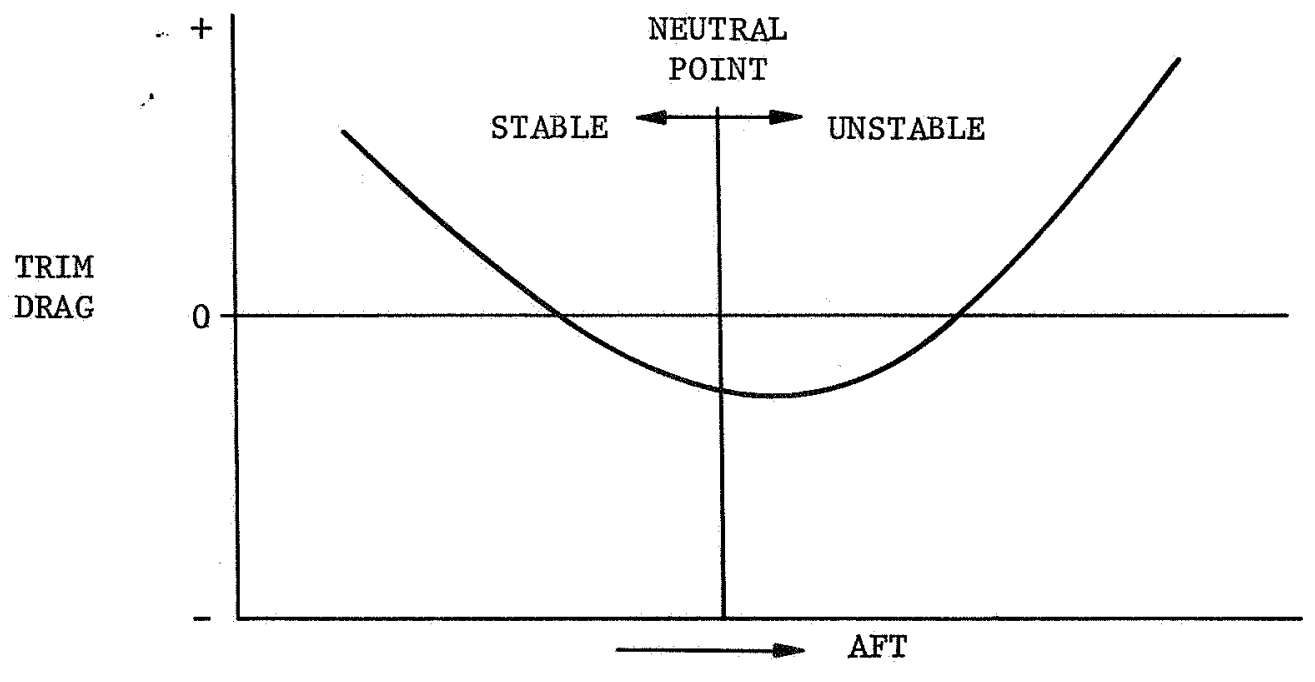

CENTER OF GRAVITY LOCATION

FIGURE 2. TRIM DRAG 


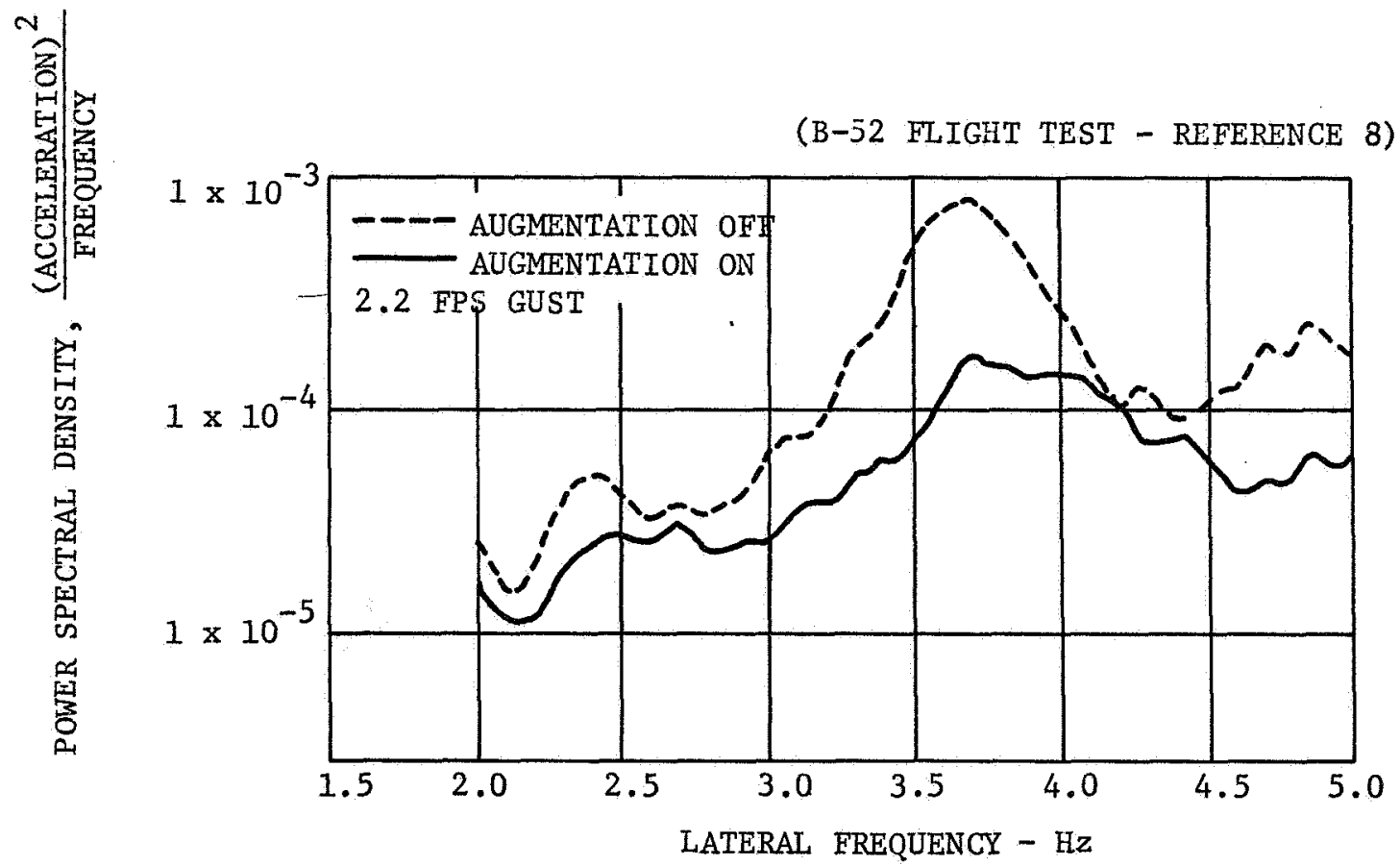

FIGURE 3. RIDE QUALITY IMPROVEMENT 


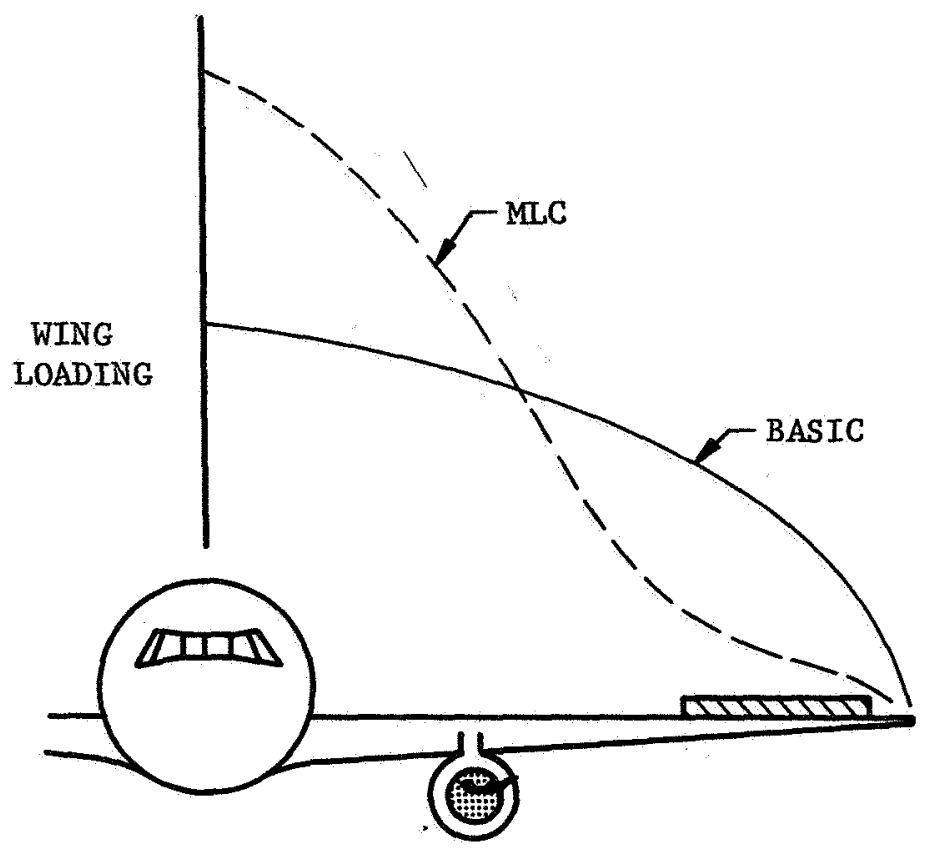

4a. UNLOADING OUTER WING

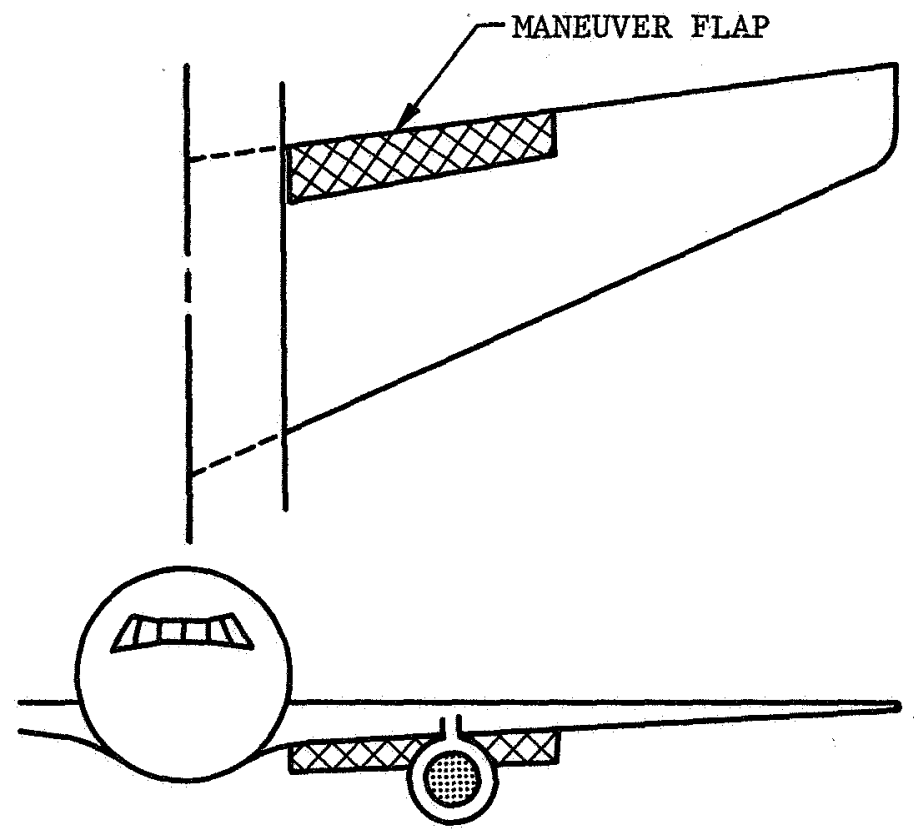

4b. LOADING INNER WING

FIGURE 4. MANEUVER LOAD CONTROL 


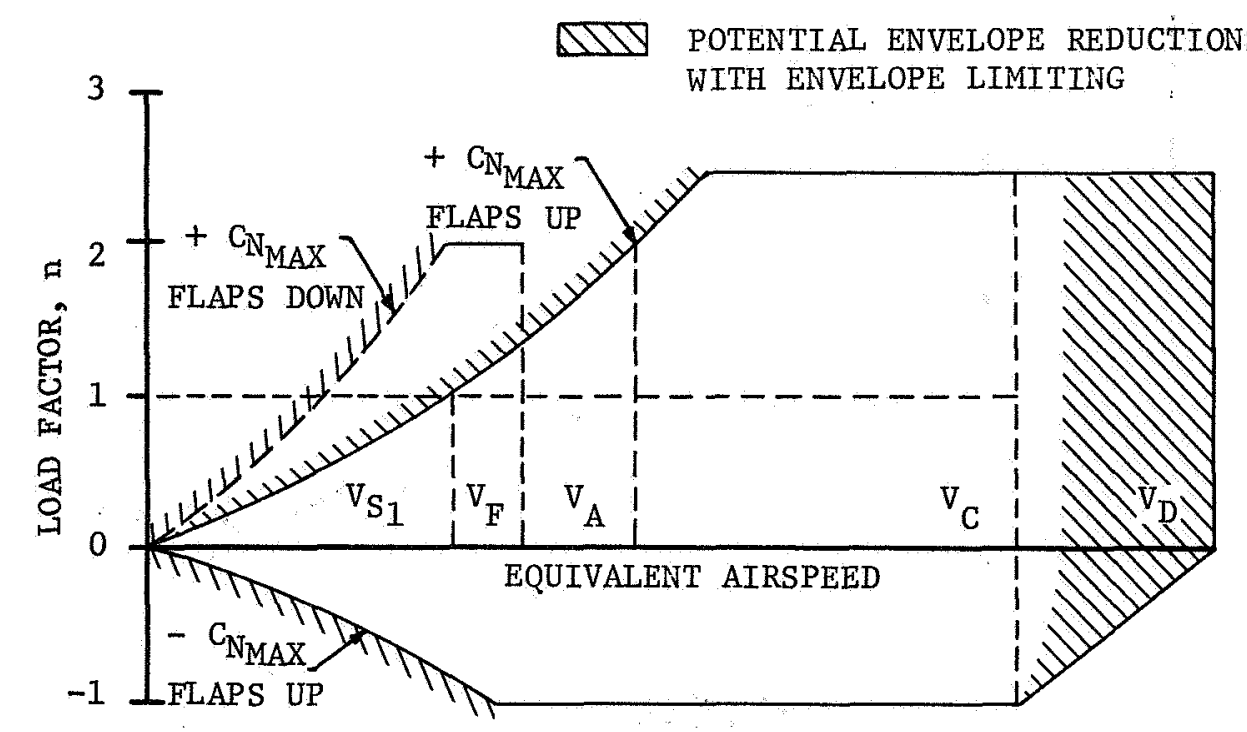

FIGURE 5. DESIGN MANEUVERING ENVELOPE

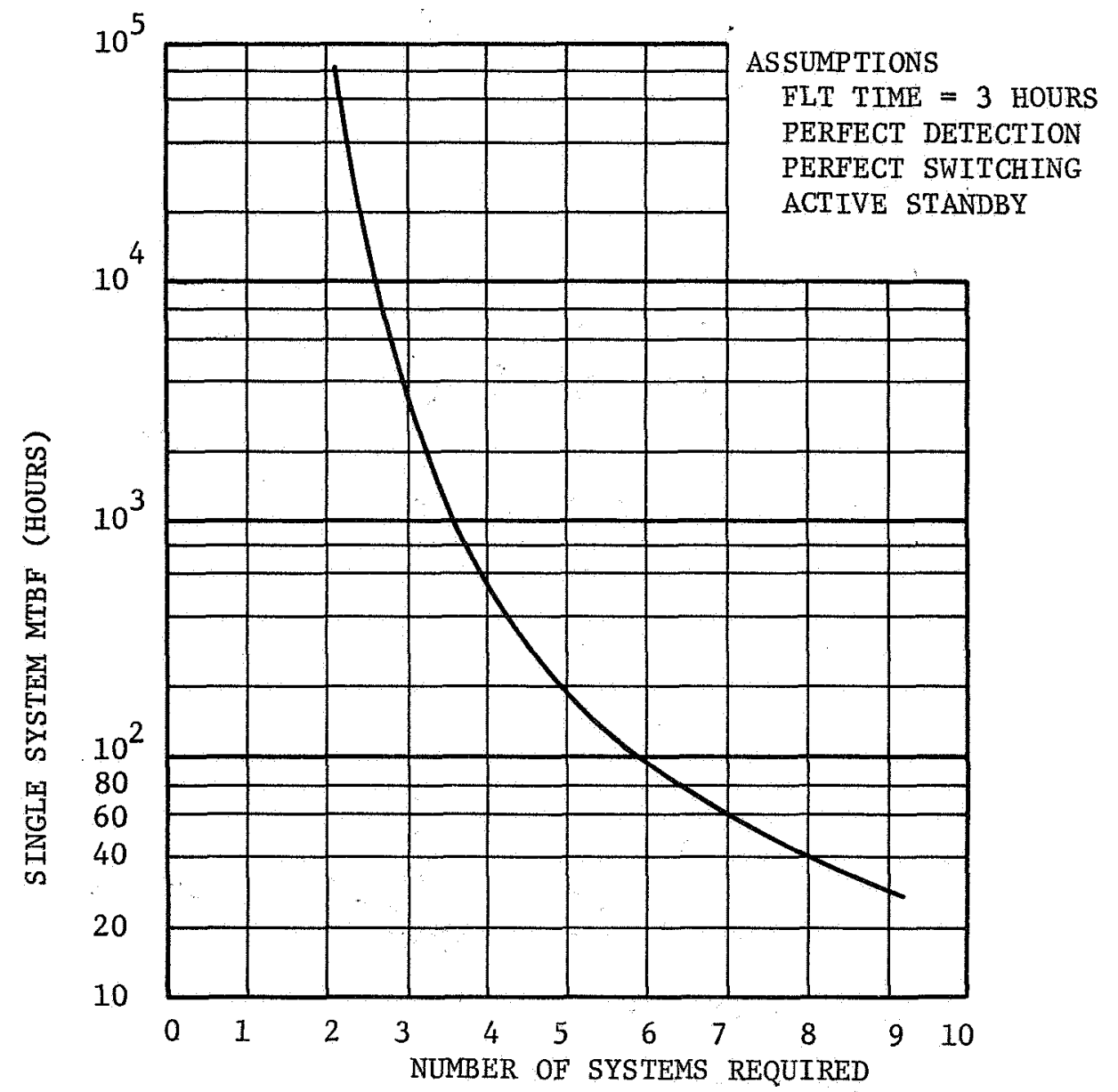
FIGURE 6. SYSTEMS REQUIRED TO PROVIDE PROBABILITY OF $10^{-9}$ FOR COMPLETE SYSTEM
FAILURE 

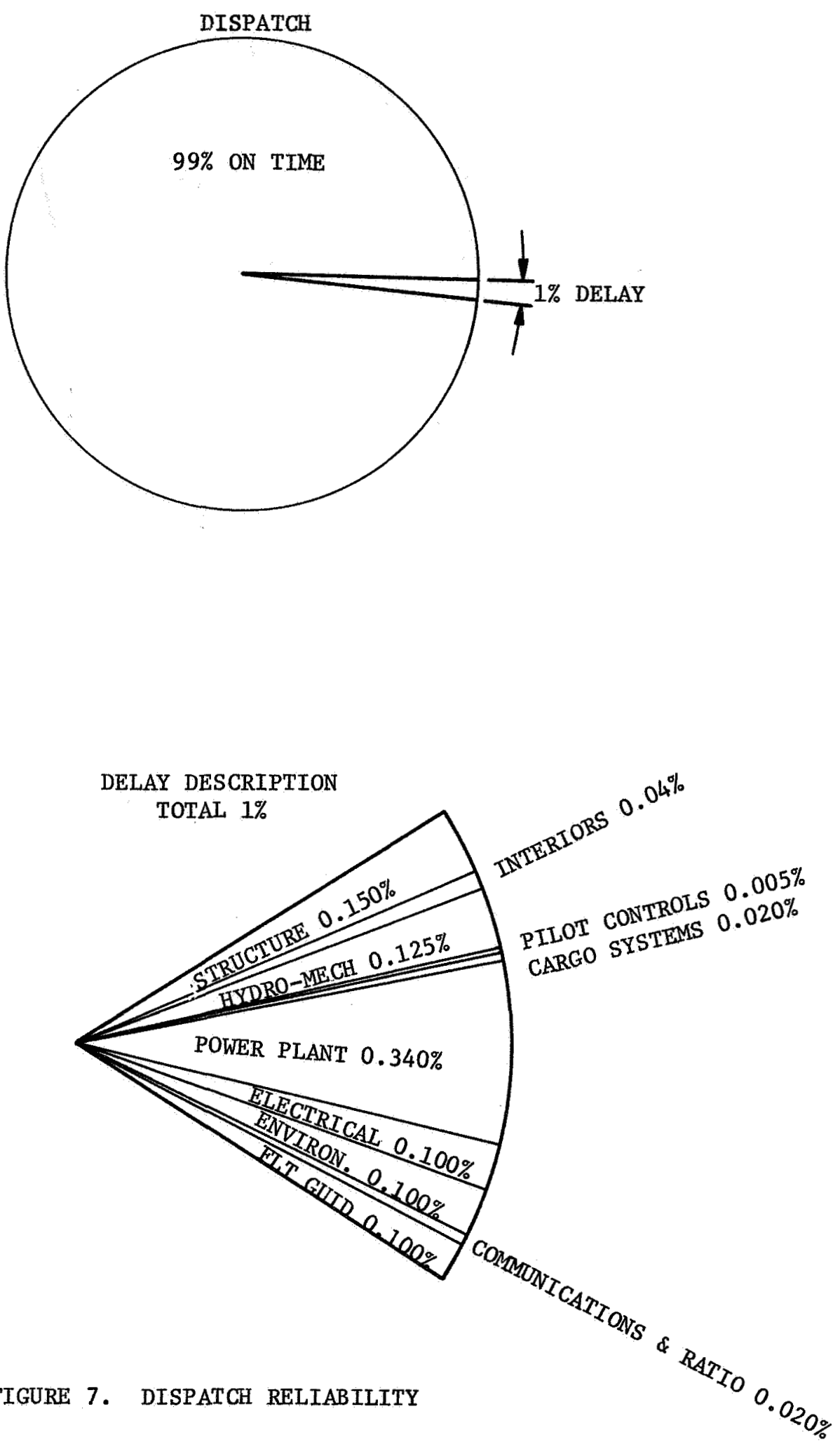

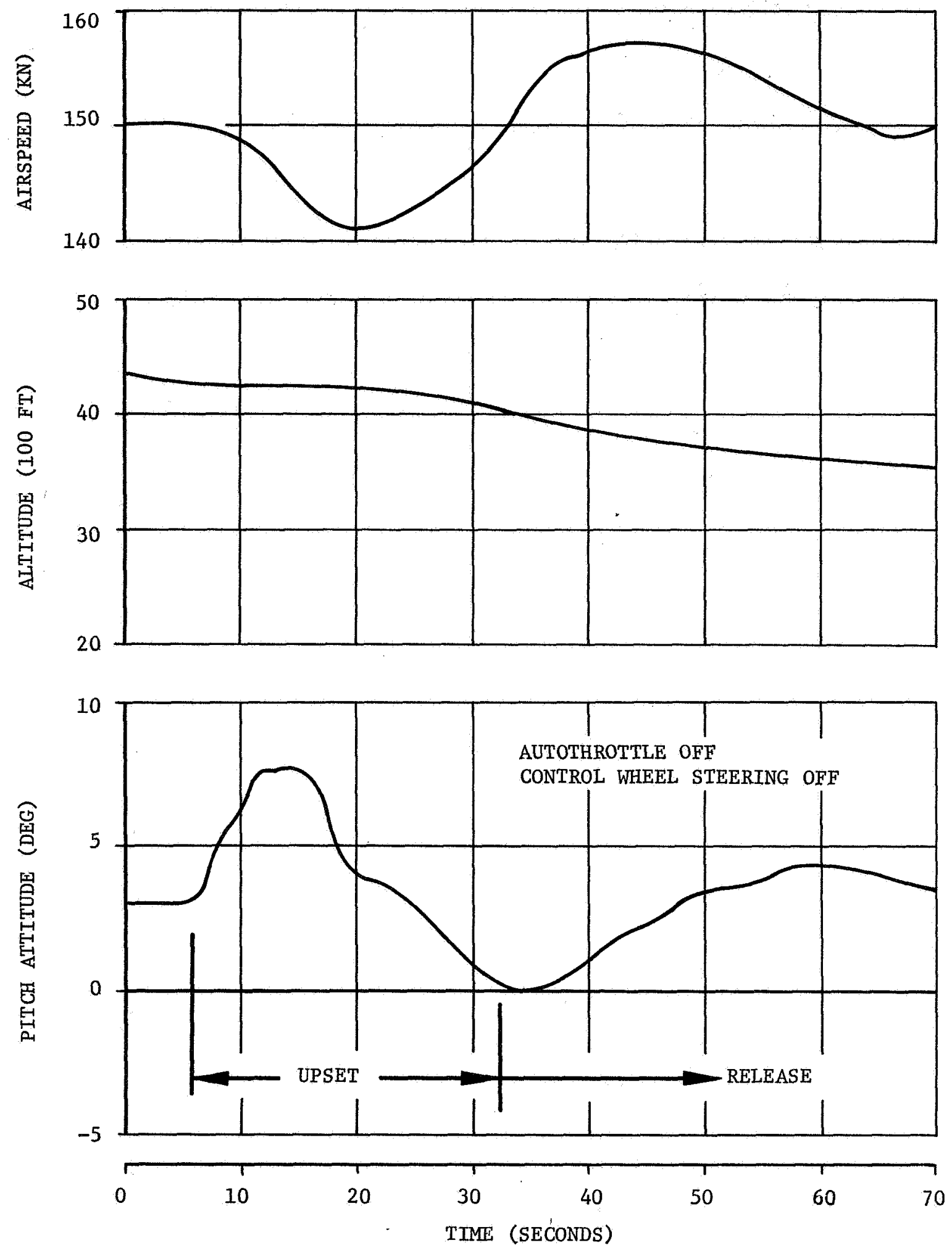

FIGURE 8a. APPROACH LONGITUDINAL STABILITY 

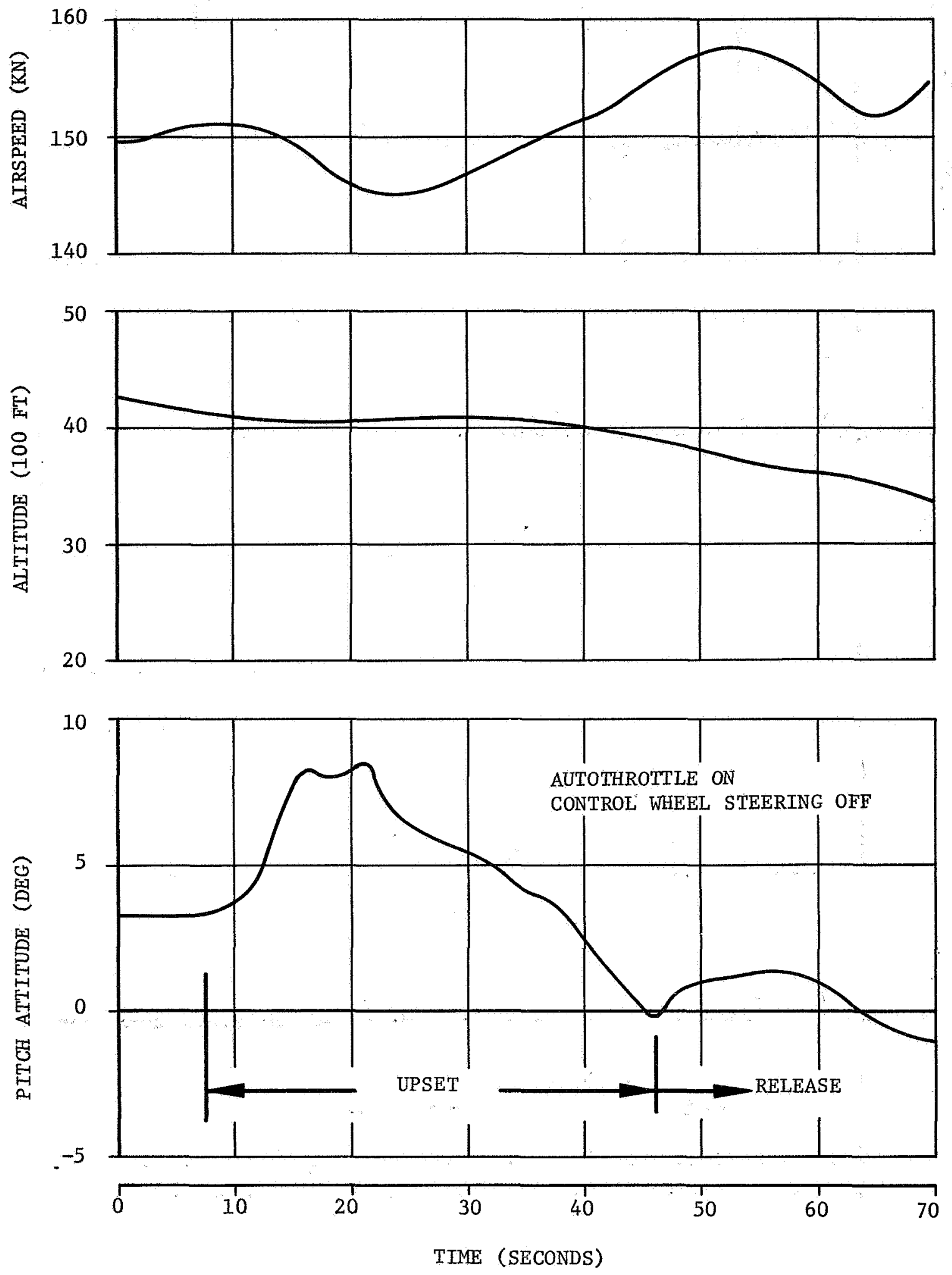

FIGURE 8b. APPROACH LONGITUDINAL STABILITY 

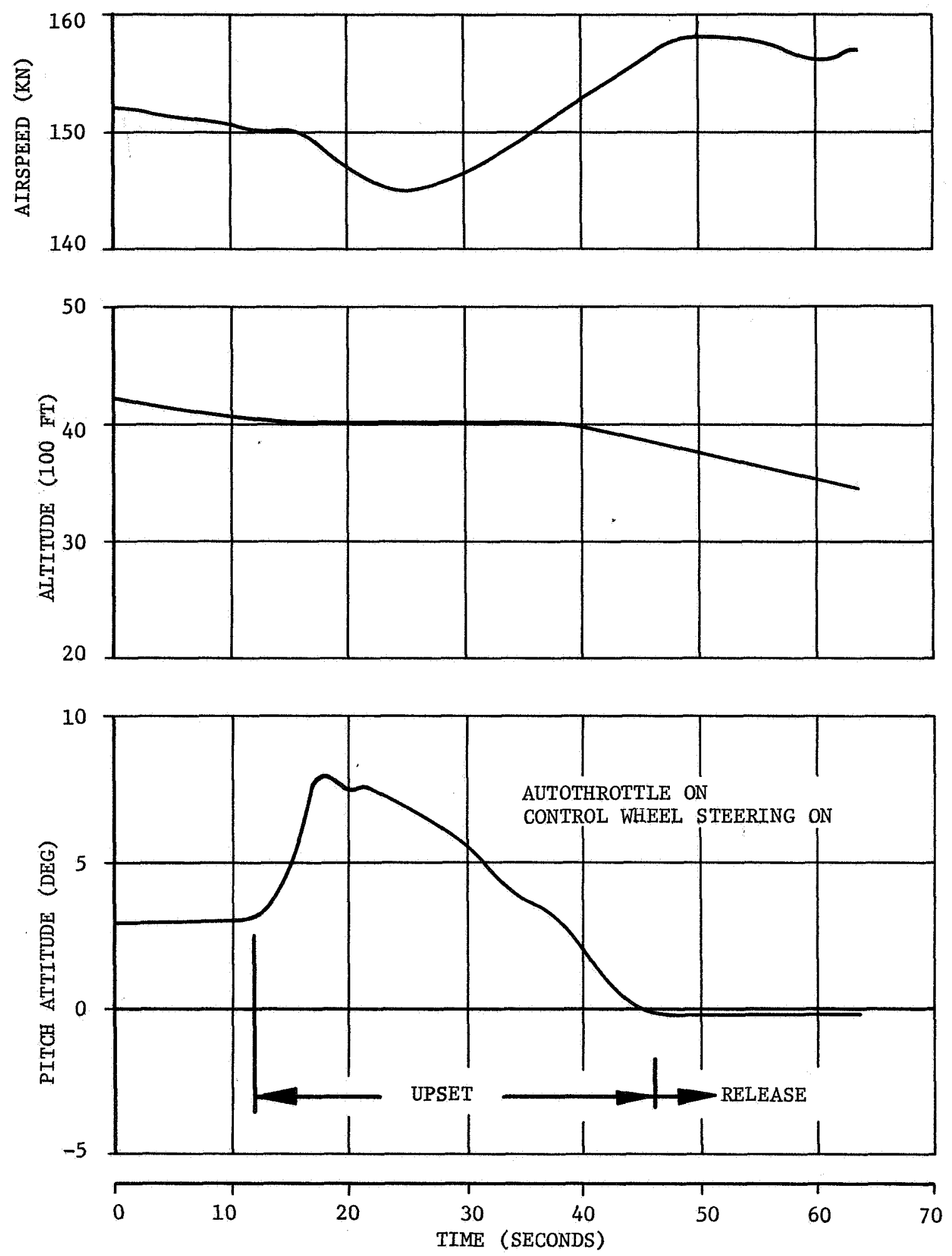

FIGURE 8c. APPROACH LONGITUDINAL STABILITY 